\title{
DESIGN OF AN INDEX TO MEASURE RURAL DEVELOPMENT. ASSESSMENT OF DIFFERENT METHODOLOGICAL APPROACHES
}

\author{
Isabel Abreu*, Francisco J. Mesías and Julián Ramajo
}

\author{
Institution: Departamento de Economía, Universidad de Extremadura (Badajoz, fjmesias@unex.es)
}

\begin{abstract}
Rural development, being a multidimensional process, must be measured by a series of indicators representing its different dimensions. Since the implementation of a policy does not affect only the targeted activity, but also contributes to the modification of the entire human environment, it cannot be monitored simply by verifying the fulfillment of its objectives. For this reason, analysts and policymakers turn to composite indicators, which are better adapted to capture the multidimensional nature of development. Given the scarcity of specific indexes to measure rural development and the shortcomings of the existing ones ( for example, lack of justification of the indicators included and their importance), it was decided to develop a new index based on a participatory process in which the stakeholders choose the most relevant indicators to be considered. Subsequently, various methodological approaches have been used, such as that of Abreu et al. (2019), that of Kynčlová et al. (2020) or the one of Michalek and Zarnekow (2012). The indices thus developed will be applied to different regions of Portugal, testing their robustness by means of a Delphi panel of experts in rural development.
\end{abstract}

Key words: rural development, index, participatory research, Delphi

\section{Introduction and objectives}

The increasingly pronounced imbalance between the level of development of rural and non-rural areas has led to an unfavourable situation of the former (Abreu et al., 2019) which are lacking not only population, but essential services. Thus, indicators such as the risk of poverty or social exclusion $(23.9 \%$ in rural areas vs. $21 \%$ in urban areas) or the level of education (60-80\% of city-dwellers have tertiary education, but less than $40 \%$ in most rural areas) show worse values in rural areas than in urban areas (Eurostat, 2019), aspects that clearly influence the job opportunities and life development of citizens.

It is within this framework that the concept of rural development (RD) arises, which could be defined as the set of initiatives aimed at fostering the modernization of rural areas, the creation of new job opportunities, the sustainability and efficiency of farms and the preservation of ecosystems (Abreu \& Mesias, 2020). RD has been promoted for decades in different parts of the world through diverse policies, which need to be evaluated to determine the effectiveness of the measures implemented, to analyze new initiatives or to decide which areas need more attention (Abreu et al., 2019). This process, already complex for any policy, is even more so in the case of RD, since, as has been mentioned, it deals with such diverse aspects as employment, modernization, sustainability and the environment which are measured through diverse indicators. These indicators would be later combined in what is called a "composite index", formed when individual indicators are compiled into a single index on the basis of an underlying model (OECD, 2008) and that would allow to measure RD.

Composite indexes are better equipped to capture the different and multi-dimensional natures of development, and for this reason policy analysts and policy makers turn to use them. However, if composite indexes are to measure progress, they need to incorporate a sufficient number of indicators so that multidimensionality is captured without compromising the interpretability of the index. Hence, the selection of underlying indicators is the result of a trade-off between possible redundancies caused by overlapping information and the risk of losing information (Kynčlová et al., 2020).

In this context, it can therefore be noted that the selection of the indicators included in the RD index is as relevant, if not more, than the way in which they are combined. Thus, although indices such as those of Kageyama (2008), Abreu et al. (2019), or Michalek \& Zarnekow (2012) use different indicators related to economic, demographic, social and environmental aspects, all of which are highly relevant for RD, they all suffer from a selection of indicators based on the literature and not on what stakeholders in rural areas consider to be really relevant for their development. Furthermore, the calculation of the values obtained by these indices is based on different methodological approaches whose validity has not been tested.

Therefore, and to overcome these limitations, this paper proposes the development of an index using the indicators selected by a panel of experts through a Delphi approach (Abreu \& Mesias, 2020). Subsequently, different aggregation methods accepted by the scientific community will be used to build a RD index: Principal Component Analysis (PCA), widely used by different authors such as (Bolcárová \& Kološta, 2015), and aggregation through geometric/arithmetic mean, as used on the HDI (Conceição, 2019) or on 
the RD Index proposed by (Abreu et al., 2019). Both methodologies are then applied to 9 different Portuguese regions and using the most recent data available for the whole set of variables from the Portuguese National Statistics Institute. At a final state, the results of the different RD indexes will be revised by a panel of Portuguese experts on $\mathrm{RD}$, who will decide which is the most accurate methodology for aggregating the variables on the construction of a RD Index.

\section{Methodology}

\subsection{Data collection}

For this paper, and in order to reflect the different realities of Portugal, it was decided to select a total of 9 NUTS-3 regions (out of a total of 25): 2 from each of the NUTS-2 regions Norte, Centro and Alentejo, plus the Algarve, Autonomous Region of Madeira and Autonomous Region of Azores (where the NUTS-2 and NUTS-3 levels coincide). The choice of the NUTS-3 level was due to this being the minimum level at which rural development policies are generally applied. In fact, the only exception is the Community-Led Local Development (CLLD), applied at a Local Administrative Unit level by the Local Action Groups.

To get a Rural Development Index with the aim to accurately monitor and evaluate the RD policies and programmes, in 2019 (Abreu \& Mesias, 2020) used the qualitative Delphi methodology. Based on the results of a panel of experts with different roles in RD, 25 indicators were selected out of an initial group of 88, to define a set within four dimensions/pillars: demography, environment, economy and social welfare. The experts also granted different weights to the indicators selected. Table 1 describes the indicators selected and the latest year for which data were available.

Table 1. Description of the indicators to be included in the RD indexes

\begin{tabular}{|c|c|c|c|}
\hline & & Abbrev. & Data year \\
\hline \multirow{5}{*}{ 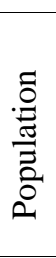 } & $\begin{array}{l}\text { Demographic Dependency Index (\%) - ratio between those } 65 \text { and older plus those } \\
\text { under } 15 \text { and the population in the working ages (ages 15-64) }\end{array}$ & DmgDep & 2019 \\
\hline & Proportion of population aged 65 or over $(\%)$ & Pop65 & 2019 \\
\hline & Proportion of population aged 16 or under $(\%)$ & Pop16 & 2019 \\
\hline & Population density (inhab $/ \mathrm{km}^{2}$ ) & PopDens & 2019 \\
\hline & Rate of natural increase (\%) & NatInc & 2019 \\
\hline \multirow{7}{*}{ 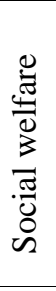 } & Coverage of essential health services (\%) & HlthServ & 2019 \\
\hline & Share of workforce with al least post-secondary education completed (\%) & WorkQual & 2011 \\
\hline & Literacy $(\%)$ - Proportion of the population aged 10 or more who can read or write & Lit & 2011 \\
\hline & Proportion of youth and adults with ICT skills (\%) & ICT & 2020 \\
\hline & Share of university students (\%) - Proportion of population in universities & Univ & 2011 \\
\hline & Proportion of conventional dwellings of regular residence with facilities $(\%)$ & Facil & 2011 \\
\hline & Proportion of population covered by a mobile network (\%) & MobNet & 2011 \\
\hline \multirow{7}{*}{ 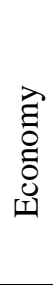 } & Average earnings per capita (€/inhab) & Earn & 2018 \\
\hline & Gross family income ( $€$ /year) & FamInc & 2018 \\
\hline & Per capita purchasing power $(\%)$ & PurcPw & 2017 \\
\hline & Unemployment rate $(\%)$ & Unemp & 2011 \\
\hline & Total income primary sector $(€)$ & IncPrim & 2018 \\
\hline & Total primary sector GVA (Gross Value Added) & PrimGVA & 2018 \\
\hline & Research and development expenditure as a proportion of GDP (\%) & R\&D & 2017 \\
\hline \multirow{6}{*}{ 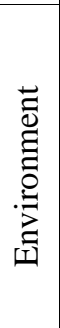 } & Renewable energy share in the total final energy consumption (\%) & RenEn & 2011 \\
\hline & Proportion of treated wastewater $(\%)$ & WasteW & 2009 \\
\hline & $\begin{array}{l}\text { Proportion of important sites for terrestrial and freshwater biodiversity that are } \\
\text { covered by protected areas }(\%)\end{array}$ & A & 19 \\
\hline & Proportion of bodies of water with good ambient water quality (\%) & WatQlt & 2018 \\
\hline & Proportion of agricultural area under productive and sustainable agriculture (\%) & SustAgr & 2009 \\
\hline & $\begin{array}{l}\text { Total expenditure per capita spent on the preservation, protection and conservation } \\
\text { of all cultural and natural heritage }(€ / \text { inhab })\end{array}$ & ExpHer & 2019 \\
\hline
\end{tabular}

SOURCE: Own elaboration, from Instituto Nacional de Estatística de Portugal and (Abreu \& Mesias, 2020)

\subsection{Aggregation methods}

These variables will be later combined to create RD Indexes through the application of different aggregation methods and considering (or not) weightings for the indicators. Aggregation methods will be based on previous research: i) RDI Abreu: arithmetic aggregation within each pillar and geometric mean of the scores for each pillar, without indicator weightings (Abreu et al., 2019; Kynčlová et al., 2020); ii) RDI PCA: PCA is used to aggregate the indicators within each pillar, then a PCA is performed using as inputs the ratings 
previously generated for each RD pillar, which are therefore weighted according to the factor loadings (Bolcárová \& Kološta, 2015); and iii) RDI A-M: a weighted arithmetic mean is calculated using the weights previously generated for each of the indicators by the Delphi experts panel (Abreu \& Mesias, 2020).

\section{Results}

Table 2 presents the original values for each indicator prior to their aggregation in the RD indexes. The data were directly collected from the official website of the National Portuguese Institute (www.ine.pt) and Portuguese Communications National Authority (www.anacom.pt).

Table 2. Values for each indicator for the nine NUTS-3 analyzed

\begin{tabular}{|c|c|c|c|c|c|c|c|c|c|c|}
\hline & & $\begin{array}{c}\text { Alto } \\
\text { Minho }\end{array}$ & $\begin{array}{l}\text { Terras de } \\
\text { Trás-os- } \\
\text { Montes }\end{array}$ & $\begin{array}{c}\text { Região de } \\
\text { Coimbra }\end{array}$ & $\begin{array}{c}\text { Beiras e } \\
\text { Serra da } \\
\text { Estrela }\end{array}$ & $\begin{array}{c}\text { Alentejo } \\
\text { Litoral }\end{array}$ & $\begin{array}{c}\text { Alto } \\
\text { Alentejo }\end{array}$ & Algarve & $\begin{array}{c}\text { Região } \\
\text { Autónoma } \\
\text { dos } \\
\text { Açores }\end{array}$ & $\begin{array}{c}\text { Região } \\
\text { Autónoma } \\
\text { da } \\
\text { Madeira } \\
\end{array}$ \\
\hline \multirow{5}{*}{ 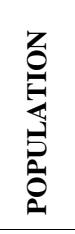 } & DmgDep & 57.60 & 67.10 & 60.00 & 64.40 & 62.80 & 63.60 & 58.40 & 43.50 & 43.00 \\
\hline & Pop65 & $25.33 \%$ & $30.27 \%$ & $25.69 \%$ & $29.17 \%$ & $26.49 \%$ & $27.46 \%$ & $21.91 \%$ & $14.94 \%$ & $16.98 \%$ \\
\hline & Pop16 & $11.22 \%$ & $9.90 \%$ & $11.81 \%$ & $10.01 \%$ & $12.09 \%$ & $11.41 \%$ & $14.95 \%$ & $15.37 \%$ & $13.11 \%$ \\
\hline & PopDens & 103.80 & 19.40 & 100.10 & 33.60 & 17.60 & 17.20 & 87.70 & 104.60 & 317.20 \\
\hline & NatInc & $-0.65 \%$ & $-1.00 \%$ & $-0.56 \%$ & $-1.09 \%$ & $-0.59 \%$ & $-1.15 \%$ & $-0.16 \%$ & $-0.06 \%$ & $-0.31 \%$ \\
\hline \multirow{7}{*}{ Ð } & HlthServ & 285.14 & 368.97 & 927.47 & 347.18 & 164.13 & 315.20 & 323.67 & 325.79 & 400.58 \\
\hline & WorkQual & $21.14 \%$ & $26.72 \%$ & $30.42 \%$ & $23.86 \%$ & $18.41 \%$ & $21.38 \%$ & $23.71 \%$ & $19.61 \%$ & $23.32 \%$ \\
\hline & Lit & $96.76 \%$ & $95.93 \%$ & $97.12 \%$ & $95.68 \%$ & $94.52 \%$ & $94.45 \%$ & $96.40 \%$ & $96.43 \%$ & $95.00 \%$ \\
\hline & ICT & $75.90 \%$ & $75.90 \%$ & $76.20 \%$ & $76.20 \%$ & $77.10 \%$ & $77.10 \%$ & $82.50 \%$ & $79.70 \%$ & $82.00 \%$ \\
\hline & Univ & $11.36 \%$ & $13.82 \%$ & $17.81 \%$ & $12.58 \%$ & $10.28 \%$ & $11.21 \%$ & $13.51 \%$ & $10.77 \%$ & $12.54 \%$ \\
\hline & Facil & $88.02 \%$ & $96.65 \%$ & $92.72 \%$ & $95.58 \%$ & $85.42 \%$ & $93.72 \%$ & $74.06 \%$ & $40.16 \%$ & $21.84 \%$ \\
\hline & MobNet & $66.73 \%$ & $60.48 \%$ & $67.69 \%$ & $67.98 \%$ & $56.71 \%$ & $79.45 \%$ & $82.17 \%$ & $88.27 \%$ & $83.75 \%$ \\
\hline \multirow{7}{*}{$\begin{array}{l}\sum_{0} \\
0 \\
0 \\
0 \\
0\end{array}$} & Earn & 978.10 & 918.10 & $1,052.50$ & 934.80 & $1,184.00$ & 968.20 & 999.00 & $1,065.40$ & $1,096.40$ \\
\hline & FamInc & $15,061.00$ & $15,774.00$ & $18,743.00$ & $15,546.00$ & $16,512.00$ & $15,958.00$ & $16,025.00$ & $17,484.00$ & $17,337.00$ \\
\hline & PurcPw & $79.65 \%$ & $79.55 \%$ & $93.69 \%$ & $78.49 \%$ & $92.45 \%$ & $85.92 \%$ & $99.10 \%$ & $87.29 \%$ & $86.51 \%$ \\
\hline & Unemp & $11.84 \%$ & $10.87 \%$ & $10.27 \%$ & $13.18 \%$ & $10.90 \%$ & $15.66 \%$ & $15.74 \%$ & $11.13 \%$ & $14.65 \%$ \\
\hline & IncPrim & 104.73 & 111.06 & 317.81 & 116.53 & 520.11 & 258.57 & 312.10 & 346.32 & 85.53 \\
\hline & PrimGVA & $2.20 \%$ & $10.81 \%$ & $2.72 \%$ & $4.01 \%$ & $20.95 \%$ & $8.64 \%$ & $3.89 \%$ & $9.24 \%$ & $1.52 \%$ \\
\hline & R\&D & $0.54 \%$ & $0.76 \%$ & $2.24 \%$ & $1.08 \%$ & $0.10 \%$ & $0.40 \%$ & $0.30 \%$ & $0.30 \%$ & $0.36 \%$ \\
\hline \multirow{6}{*}{ 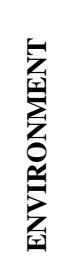 } & RenEn & $0.21 \%$ & $0.15 \%$ & $0.20 \%$ & $0.16 \%$ & $0.21 \%$ & $0.11 \%$ & $0.38 \%$ & $0.25 \%$ & $1.43 \%$ \\
\hline & WasteW & $100.00 \%$ & $77.56 \%$ & $90.33 \%$ & $100.00 \%$ & $100.00 \%$ & $90.00 \%$ & $100.00 \%$ & $46.00 \%$ & $87.00 \%$ \\
\hline & ProtectA & $16.00 \%$ & $24.40 \%$ & $0.19 \%$ & $19.00 \%$ & $10.30 \%$ & $9.30 \%$ & $9.40 \%$ & $24.20 \%$ & $58.20 \%$ \\
\hline & WatQlt & $75.20 \%$ & $68.00 \%$ & $45.00 \%$ & $40.70 \%$ & $54.90 \%$ & $26.90 \%$ & $76.20 \%$ & $65.00 \%$ & $65.00 \%$ \\
\hline & SustAgr & $0.49 \%$ & $2.49 \%$ & $0.20 \%$ & $5.78 \%$ & $0.34 \%$ & $3.95 \%$ & $0.89 \%$ & $0.14 \%$ & $2.15 \%$ \\
\hline & ExpHer & 65.53 & 111.17 & 67.34 & 84.97 & 98.19 & 142.36 & 138.59 & 50.16 & 118.67 \\
\hline
\end{tabular}

SOURCE: Own elaboration, from Instituto Nacional de Estatística de Portugal and (Abreu \& Mesias, 2020)

All the data were normalized, a procedure required prior to any data aggregation, as the indicators in a data set often have different measurement units (OECD, 2008) and it wouldn't be possible to comparable them otherwise. Using the range within [0-1] to standardize the variables, the meaning of the indicators Demographic Dependency Index, and Proportion of Population Aged 65 or over were reversed using an "inverse" normalization: assigning the value of 0 to the NUTS-3 with the highest values in these indicators, and 1 to the lowest ones as used by other authors as applied by (Kynčlová et al., 2020).

Table 3 presents the normalized results of the three RD Indexes obtained by applying the aggregation methods explained in the Methodology section to the data presented in table 2.

Table 3. Values for each indicator for the nine NUTS-3 analyzed

\begin{tabular}{|l|c|c|c|}
\hline & RDI_Abreu & RDI_A-M & RDI_PCA \\
\hline Alto Minho & 0,34 & 0,13 & 0,29 \\
\hline Terras de Trás-os-Montes & 0,00 & 0,11 & 0,00 \\
\hline Região de Coimbra & 0,78 & 0,89 & 0,27 \\
\hline Beiras e Serra da Estrela & 0,05 & 0,02 & 0,01 \\
\hline Alentejo Litoral & 0,37 & 0,38 & 0,18 \\
\hline Alto Alentejo & 0,17 & 0,00 & 0,09 \\
\hline
\end{tabular}




\begin{tabular}{|l|l|l|l|}
\hline Algarve & 0,94 & 0,84 & 0,70 \\
\hline Região Autónoma dos Açores & 0,74 & 0,73 & 1,00 \\
\hline Região Autónoma da Madeira & 1,00 & 1,00 & 0,99 \\
\hline
\end{tabular}

The results in Table 2 clearly show that there is a strong correlation between Abreu and A-M indexes, with the NUTS-3 ranked with high similarity. However, the NUTS-3 with the lowest value is different when applying Abreu and PCA (Terras de Trás-os-Montes), or M-A (Alto Alentejo), but in fact both regions are strongly needed for public policies to reverse depopulation and aging, which leverage their development.

Regarding the NUTS-3 with the highest value, Abreu and A-M indicate the Região Autónoma da Madeira. However, applying PCA this is the territory with the second highest value, giving the first place to Região Autónoma dos Açores, but with a RDI result really close to the first one.

However, although the results are similar in the extreme values, the situation is different for the middle ones. For example, when analyzing Região de Coimbra, Abreu and A-M rank it in the third or second place, respectively, but the PCA method position this NUTS-3 in the fifth position, after Alto Minho, which raises some doubts about its reliability, as Coimbra is one of the most industrialized and developed regions of Portugal. In fact, Abreu and A-M rank Alto Minho on the seventh place, a figure that matches with a low density territory, strongly marked by aging.

\section{Conclusions}

Despite the relevance of rural development in today's policies and society, the lack of indexes specifically designed for the evaluation of rural areas makes it difficult to design and implement policies, or to adjust those that, while already being implemented, may not generate the expected results. It also makes it difficult to identify areas where the use of public funds would be more effective, resulting in less efficient rural development policies.

Although various approaches have been developed to generate indexes capable of measuring rural development, all of them suffer from a lack of involvement of interest groups at the moment of deciding which indicators are really relevant for the inhabitants of rural areas when it comes to defining and evaluating rural development.

This has been corrected in this work by using a series of indicators previously generated by a panel of experts in rural development, which have become the inputs for generating various rural development indices by applying different methodologies.

\section{Bibliography}

Abreu, I., y Mesias, F. J. (2020). The assessment of rural development: Identification of an applicable set of indicators through a Delphi approach. Journal of Rural Studies.

https://doi.org/10.1016/j.jrurstud.2020.10.045

Abreu, I., Nunes, J. M., y Mesias, F. J. (2019). Can Rural Development Be Measured? Design and Application of a Synthetic Index to Portuguese Municipalities. Social Indicators Research, 145(3), 11071123. https://doi.org/10.1007/s11205-019-02124-w

Bolcárová, P., y Kološta, S. (2015). Assessment of sustainable development in the EU 27 using aggregated SD index. Ecological Indicators, 48, 699-705. https://doi.org/10.1016/j.ecolind.2014.09.001

Conceição, P. (2019). Human Development Report 2019: beyond income, beyond averages, beyond today. In United Nations Development Program.

Eurostat. (2019). Eurostat Regional Yearbook. 2019 edition. Publications Office of the European Union. https://doi.org/10.27585/1522

Kageyama, A. (2008). Desenvolvimento rural : conceitos e aplicação ao caso brasileiro. UFRGS Editora. Kynčlová, P., Upadhyaya, S., y Nice, T. (2020). Composite index as a measure on achieving Sustainable Development Goal 9 (SDG-9) industry-related targets: The SDG-9 index. Applied Energy, 265. https://doi.org/10.1016/j.apenergy.2020.114755

Michalek, J., y Zarnekow, N. (2012). Application of the Rural Development Index to Analysis of Rural Regions in Poland and Slovakia. Social Indicators Research, 105(1), 1-37.

https://doi.org/10.1007/s11205-010-9765-6

OECD. (2008). Handbook on Constructing Composite Indicators. In OECD Publications. 